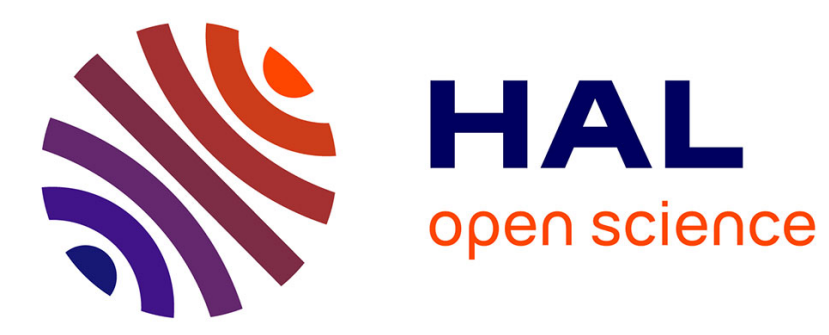

\title{
Synthesis of powellite-rich glasses for high level waste immobilization
}

\author{
Tatiana Taurines, Bruno Boizot
}

\section{To cite this version:}

Tatiana Taurines, Bruno Boizot. Synthesis of powellite-rich glasses for high level waste immobilization. Conference on the Structure of Non-Crystalline Materials (NCM11), Jun 2010, Paris, France. pp.27232725, 10.1016/j.jnoncrysol.2011.02.024 . hal-00599090

\section{HAL Id: hal-00599090 \\ https://hal-polytechnique.archives-ouvertes.fr/hal-00599090}

Submitted on 8 Jun 2011

HAL is a multi-disciplinary open access archive for the deposit and dissemination of scientific research documents, whether they are published or not. The documents may come from teaching and research institutions in France or abroad, or from public or private research centers.
L'archive ouverte pluridisciplinaire HAL, est destinée au dépôt et à la diffusion de documents scientifiques de niveau recherche, publiés ou non, émanant des établissements d'enseignement et de recherche français ou étrangers, des laboratoires publics ou privés. 


\title{
Synthesis of powellite-rich glasses for high level waste immobilization
}

\author{
T. Taurines ${ }^{1}$, B. Boizot ${ }^{1}$ \\ (1) Laboratoire des Solides Irradiés, UMR 7642 CEA-CNRS-Ecole Polytechnique, 91128
}

Palaiseau, France

\begin{abstract}
Increasing amounts of $\mathrm{MoO}_{3}$ were added to $\mathrm{SiO}_{2}-\mathrm{B}_{2} \mathrm{O}_{3}-\mathrm{Na}_{2} \mathrm{O}-\mathrm{CaO}-\mathrm{Al}_{2} \mathrm{O}_{3}$ glasses in order to trap molybdenum as powellite (nominally $\mathrm{CaMoO}_{4}$ ). Different heat treatments were performed to study their influences on powellite crystallization by X-ray diffraction and EPR. The glass compositions studied in this work lead to glass-ceramics rich in $\mathrm{CaMoO}_{4}$, up to $\left[\mathrm{MoO}_{3}\right]=5 \mathrm{~mol} \%$ no poorly durable $\mathrm{Na}_{2} \mathrm{MoO}_{4}$ phase was identified by XRD. Trivalent actinides surrogates $\left(\mathrm{Gd}^{3+}\right)$ were observed to incorporate into $\mathrm{CaMoO}_{4}$ crystals.
\end{abstract}

Keywords: molybdenum, glass-ceramic, powellite, XRD, EPR

*Corresponding author : Tatiana Taurines: Laboratoire des Solides Irradiés, UMR 7642 CEACNRS-Ecole Polytechnique, 91128 Palaiseau Cedex, France. Tel: 331693345 02; e-mail: tatiana.taurines@cea.fr 


\section{Introduction}

Spent fuel from GCR (Gas Cooled Reactors), mainly worked in France and U.K. during the second part of the $20^{\text {th }}$ century is highly concentrated in molybdenum. During vitrification processes, Mo-rich glasses can lead to the separation of a poorly durable phase (called “yellow phase") containing radioactive elements like ${ }^{137} \mathrm{Cs}$ [1]. Indeed, in glasses prepared under neutral or oxidizing atmospheres, molybdenum appears mainly as $\mathrm{Mo}^{6+}$ with a low solubility ( 1 mol\%) and crystallize in alkali or alkaline-earth molybdates during melt cooling and heat treatments. Crystallization of the poorly durable phase $\mathrm{Na}_{2} \mathrm{MoO}_{4}$ must be avoided to keep a low leachability of the immobilization glass matrices.

Glass-ceramics are known to exhibit improved properties with respect to glasses as mechanical and thermal properties [2]. Besides glass-ceramics are easier to process than ceramics since no high pressures or extremely high temperatures are needed. Therefore, new glass ceramics formulations [3,4] were studied to trap up to $12 \mathrm{wt} \%$ of molybdenum as powellite $\mathrm{CaMoO}_{4}$ which is a stable phase in vitreous medium.

In this work, we synthesized calcium enriched aluminoborosilicate glasses to study the $\mathrm{CaMoO}_{4}$ formation and to obtain a simplified model for powellite-rich glass-ceramics. Heat treatments were performed to control the content and the size of crystallites and the structural changes were studied by X-ray diffraction (XRD) and electron paramagnetic resonance (EPR) measurements. 


\section{Experimental methods}

For this study, we prepared glasses in the system: $\mathrm{SiO}_{2}-\mathrm{B}_{2} \mathrm{O}_{3}-\mathrm{Na}_{2} \mathrm{O}-\mathrm{CaO}-\mathrm{Al}_{2} \mathrm{O}_{3}$. A small quantity of $\mathrm{Gd}_{2} \mathrm{O}_{3}(0.15 \mathrm{~mol} \%)$ was added to all glasses to study the speciation of rare earth elements between the glassy and crystalline phases. For that purpose, $\mathrm{Gd}^{3+}$ was used as a spectroscopic probe for EPR measurements. Indeed, EPR spectroscopy is a quantitative tool for analyzing ion speciation and $\mathrm{Gd}^{3+}$ ion EPR spectra are known in glasses [5,7].

Two series were prepared where $\mathrm{x}=0.5,2.5,5,7 \mathrm{~mol} \%$ corresponds to $\mathrm{MoO}_{3}$ content:

(i) $\mathrm{M} 1 \mathrm{x}$ with $\mathrm{MoO}_{3}$ and $\mathrm{CaO}$ introduced in stoichiometric proportions (0.9985$2 \mathrm{x} / 100)\left(65.04 \mathrm{SiO}_{2}-17.22 \mathrm{~B}_{2} \mathrm{O}_{3}-13.67 \mathrm{Na}_{2} \mathrm{O}-4.14 \mathrm{Al}_{2} \mathrm{O}_{3}\right)-\mathrm{x} \mathrm{CaO}-\mathrm{x} \mathrm{MoO}_{3}-0.15$ $\mathrm{Gd}_{2} \mathrm{O}_{3}$ (in $\mathrm{mol} \%$ ).

(ii) $\mathrm{M} 2 \mathrm{x}$ with $\mathrm{Ca}$ introduced in excess $(0.9985-2 \mathrm{x} / 100)\left(61.16 \mathrm{SiO}_{2}-16.28 \mathrm{~B}_{2} \mathrm{O}_{3}-12.85\right.$ $\left.\mathrm{Na}_{2} \mathrm{O}-3.88 \mathrm{Al}_{2} \mathrm{O}_{3}-5.82 \mathrm{CaO}\right)-\mathrm{x} \mathrm{CaO}-\mathrm{x} \mathrm{MoO}_{3}-0.15 \mathrm{Gd}_{2} \mathrm{O}_{3}($ in mol\%). For all $\mathrm{M} 2 \mathrm{x}$ glasses we have $\left[\mathrm{CaCO}_{3}\right]>\left[\mathrm{MoO}_{3}\right]+\left[\mathrm{Al}_{2} \mathrm{O}_{3}\right]$ so that more $\mathrm{Ca}^{2+}$ ions are available to crystallize into powellite.

Parent glasses were prepared by mixing desired amount of reagent grade $\mathrm{SiO}_{2}, \mathrm{H}_{3} \mathrm{BO}_{3}$, $\mathrm{Na}_{2} \mathrm{CO}_{3}, \mathrm{Al}_{2} \mathrm{O}_{3}, \mathrm{CaCO}_{3}, \mathrm{MoO}_{3}$ and $\mathrm{Gd}_{2} \mathrm{O}_{3}$. Each batch $(\sim 30 \mathrm{~g})$ was melt at $1500^{\circ} \mathrm{C}$ for $3 \mathrm{~h}$ and ground before remelting $\left(1500^{\circ} \mathrm{c}\right.$ for $\left.2 \mathrm{~h}\right)$ for homogeneity. During the first melting, a plateau at $700^{\circ} \mathrm{C}$ during 4 hours is necessary for decarbonation of $\mathrm{Na}_{2} \mathrm{CO}_{3}$ and $\mathrm{CaCO}_{3}$. Samples are quenched onto a copper plate or into water and are annealed at $500^{\circ} \mathrm{C}$ for $2 \mathrm{~h}$ to relieve internal stresses. Chemical analysis by EDX (energy dispersive X-ray analysis) of glasses showed that the final $\mathrm{Na}$ content is about $40 \%$ lower after the melting process, other elements contents seemed to be unchanged (boron content was not measured).

Ceramics were elaborated with two chemical compositions: pure powellite $\mathrm{CaMoO}_{4}$ and powellite containing $0.15 \mathrm{~mol} \%$ of $\mathrm{Gd}_{2} \mathrm{O}_{3}$ (mentioned later as $\mathrm{CaMoO} 4-\mathrm{Gd}$ ). Appropriate amounts of reagents were grounded and pellets were obtained with a mechanical press. Ceramics were then sintered at $1150^{\circ} \mathrm{C}$ for $12 \mathrm{~h}$ under air.

Two different crystallization methods were investigated to control size and concentration of powellite.

(i) The first method consists of a nucleation stage at $T_{n}$ and a crystal growth stage at $\mathrm{T}_{\mathrm{c}}$ on annealed parent glasses. Samples were treated at $\mathrm{T}_{\mathrm{n}}=650^{\circ} \mathrm{C}$ or $\mathrm{T}_{\mathrm{n}}=950^{\circ} \mathrm{C}$ during $2 \mathrm{~h}$ and then transferred to a preheated furnace at $\mathrm{T}_{\mathrm{c}}=1050^{\circ} \mathrm{C}$ or $1100^{\circ} \mathrm{C}$ for $2 \mathrm{~h}$ and $20 \mathrm{~h}$. 
(ii) The second method consists of a rapid cooling $(0.5 \mathrm{~h})$ from $1500^{\circ} \mathrm{C}$ following the $2^{\text {nd }}$ melting to a crystal growth stage at $\mathrm{T}_{\mathrm{c}}=1100^{\circ} \mathrm{C}$ during $4 \mathrm{~h}$ or $22 \mathrm{~h}$. The samples were then quenched to room temperature in water or in air.

All samples were reduced into powder $(<40 \mu \mathrm{m})$ and studied by (XRD). The diffraction data were collected at room temperature on a Panalytical (Philips) diffractometer in the Bragg-Brentano geometry with a $\mathrm{Cu}$ anti-cathode: $\mathrm{K}_{\alpha 1}, \mathrm{~K}_{\alpha 2}(\lambda=1.54560 \AA$ and $\lambda=1.54439$ $\AA, 40 \mathrm{kV}, 40 \mathrm{~mA}$ ) and a linear detector. The angular range $15^{\circ}-60^{\circ}$ was scanned in $0.02^{\circ}$ steps with a minimum counting time of $90 \mathrm{~s} / \mathrm{step}$. Particular attention was paid to probe the same volume of powder for all samples during XRD measurements. EPR measurements were effected at room temperature on a X band $(v=9.86 \mathrm{GHz})$ EMX Bruker EPR spectrometer using a $100 \mathrm{kHz}$ field modulation, 3 Gauss of amplitude modulation. Microwave powers (MP) between 1 and $50 \mathrm{~mW}$ were used for studying $\mathrm{Gd}^{3+}$ and $\mathrm{Mo}^{5+}$ ions environments and for analyzing their microwave saturation properties.

\section{Results and discussion}

Figure 1 shows the XRD patterns of samples $\mathrm{M} 1 \mathrm{x}$ and $\mathrm{M} 2 \mathrm{x}$ with increasing Mo concentration. The broad line around $22^{\circ} 2 \theta$ is attributed to the WAXS (Wide Angle X-ray Scattering) signal of the amorphous aluminoborosilicate phase. Powellite is the only crystalline phase observed in the various XRD patterns of glass ceramics with $\left[\mathrm{MoO}_{3}\right] \leq 5$ mol\%. For the highest Mo concentration ( $7 \mathrm{~mol} \%$ ), samples are heterogeneous. However M27 is more homogeneous than M17 since there are only small inclusions in the M27 bulk compared to a phase completely separated from the M17 bulk. Moreover a thin yellow layer is observed on the M17 sample after quenching on a copper plate. The XRD patterns on figure $1(\mathrm{~g})$ and $(\mathrm{h})$ show that the separated phase and the inclusions are composed of $\mathrm{CaMoO}_{4}$ (JCPDS 01-077-2238), $\mathrm{Na}_{2} \mathrm{MoO}_{4}$ (JCPDS 01-073-1797) and $\mathrm{Na}_{2} \mathrm{MoO}_{4}, 2 \mathrm{H}_{2} \mathrm{O}$ (JCPDS 01070-1710). The appearance of a $\mathrm{Na}_{2} \mathrm{MoO}_{4}, 2 \mathrm{H}_{2} \mathrm{O}$ phase could be due to hydration of the $\mathrm{Na}_{2} \mathrm{MoO}_{4}$ phase during samples storage after the synthesis. In addition, the relative proportion of alkali molybdates in the separated phase of M17 sample is qualitatively higher than in the inclusions of the M27 sample. In this work, the calcium content in the parent glass seems to be an important parameter to control samples homogeneity and limit alkali molybdates precipitation for high $\left[\mathrm{MoO}_{3}\right]$ content. From now on we will focus on the $\mathrm{M} 2 \mathrm{x}$ series. 
The EPR spectra for the M2x series, illustrated in figure 2, show different well-known lines typical for $\mathrm{Gd}^{3+}$ and $\mathrm{Mo}^{5+}$ ions in glass. For [MoO3] $\geq 2.5 \mathrm{~mol} \%$ a complex signal composed of various lines is observed. The lines at $\mathrm{g} \sim 2.0, \mathrm{~g} \sim 2.8$ and $\mathrm{g} \sim 6.0$ correspond to the so called "U" spectrum and are attributed to $\mathrm{Gd}^{3+}$ in network modifier position $\left(\mathrm{Gd}^{3+}{ }_{[\mathrm{n} . \mathrm{m}]}\right)[6]$. The signal at $\mathrm{g}=4.6$ is attributed to $\mathrm{Gd}^{3+}$ characterized by high crystalline field acting as network former $\left(\mathrm{Gd}^{3+}{ }_{[\mathrm{n} . \mathrm{f}]}\right)[6]$. The broad resonance can be ascribed to magnetic oxide clusters of $\mathrm{Gd}^{3+}$ ions, linked through the oxygen bridges [7]. The last EPR line at $\mathrm{g}=1.91$ could be attributed to $\mathrm{Mo}^{5+}$ diluted in the glassy phase $[8,9,10]$. The increase of $\mathrm{MoO}_{3}$ content and therefore the powellite phase formation lead to different changes on the M2x samples EPR spectra. The first is a decrease of $\mathrm{Gd}^{3+}{ }_{[\mathrm{n} . \mathrm{f}]} / \mathrm{Gd}^{3+}{ }_{[\mathrm{n} . \mathrm{m}]}$ ratio (see inset in figure 2). We approximated this ratio by the ratio of the intensity of the line at $g=4.6$ over the intensity of the line at $g=6$ since the lines at $g=2$ and 2.8 are superimposed on other EPR signals. The second change is the increase of the $\mathrm{Mo}^{5+}$ line with $\mathrm{MoO}_{3}$ content in glass as reported in [9]. The last change is the appearance with the Mo doping level of a new complex EPR component which is described in details below.

Figure 3 shows the EPR spectra of the $\mathrm{CaMoO}_{4}$ ceramics with and without gadolinium. The only EPR lines in common between the two ceramics are the six lines centered at $g=2$ attributed to diluted $\mathrm{Mn}^{2+}$ ions [11] and correlated to the presence of this impurity in the reagents used for the synthesis. As a consequence, the other EPR lines on the $\mathrm{CaMoO}_{4}-\mathrm{Gd}$ spectra could be associated to $\mathrm{Gd}^{3+}$ ions incorporated into the powellite crystalline phase. The circled lines on the figure 2 are all observed on the $\mathrm{CaMoO}_{4}-\mathrm{Gd}$ EPR spectrum. Moreover, microwave saturation properties of the $\mathrm{Gd}^{3+}$ EPR spectrum suggest that this ion is inserted in several sites in the powellite structure, further studies will be made to determine the nature of the different $\mathrm{Gd}^{3+}$ ion sites in the powellite structure.

Two different heat treatments were performed on samples to change the microstructure. At the macroscopic scale, a sharp difference between the two treatments is visible by eye. Indeed, for the M225 samples no differences are seen for samples heat treated by nucleation $(2 \mathrm{~h})$ and crystal growth $(20 \mathrm{~h})$ at $1100^{\circ} \mathrm{C}$, on the contrary powellite needles (see figure 4,d ) are clearly visible in the M225 heat treated at $1100^{\circ} \mathrm{C}$ for the crystal growth stage during $22 \mathrm{~h}$. After various heat treatments, only powellite is observed by XRD in addition to the aluminoborosilicate glass for $\left[\mathrm{MoO}_{3}\right] \leq 5 \mathrm{~mol} \%$. Nevertheless, the gaussian width does not evolve as expected since the FWHM (full width at half maximum) does not decrease with heat treatments duration. We have therefore no increase of the coherent domains size of powellite crystals during the growth stage. Moreover, no increase in powellite concentration 
was detected by XRD, which could be due to an inappropriate nucleation temperature. The EPR study reveals a decrease of $\mathrm{Mo}^{5+}$ ions (see figure 4,c) in glass with heat treatment duration for all samples. This result could be associated to a change in redox couple of the elements during the nucleation and crystal growth stage. No significant change in the EPR lines associated with $\mathrm{Gd}^{3+}$ incorporated into the powellite phase is observed. The $\mathrm{Gd}^{3+}{ }_{[\text {n.f] }} / \mathrm{Gd}^{3+}{ }_{[\mathrm{n} . \mathrm{m}]}$ ratio changes with heat treatments but no global trends with durations or temperatures were found. In addition, this work shows that $\mathrm{Gd}^{3+}$ is a good EPR probe for studying the speciation of this ion between the different sites of the glassy and crystalline phases as a function of synthesis and heat treatments conditions.

The synthesis parameters used in this work have shown that we can obtain a two phase system of glass-ceramics. The fact that only $\mathrm{CaMoO}_{4}$ is detected by XRD in samples for $\left[\mathrm{MoO}_{3}\right] \leq 5 \mathrm{~mol} \%$ could be due to the high percentage of $\mathrm{B}_{2} \mathrm{O}_{3}$ [9,12] combined with the addition of $\mathrm{Al}_{2} \mathrm{O}_{3}$ introduced in the glass composition [13]. In that case, the sodium acts as a charge compensator of $\mathrm{BO}_{4}{ }^{-}$and $\mathrm{AlO}_{4}{ }^{-}$units and is not available for the crystallization in alkali molybdates. EPR spectroscopy has shown the presence of different paramagnetic species like $\mathrm{Mo}^{5+}(\mathrm{S}=1 / 2)$ in the glassy phase and $\mathrm{Gd}^{3+}(\mathrm{S}=7 / 2)$ in the powellite phase. The decrease of $\mathrm{Gd}^{3+}{ }_{[\mathrm{n} . \mathrm{f}]} / \mathrm{Gd}^{3+}{ }_{[\mathrm{n} . \mathrm{m}]}$ ratio in the glassy phase is associated to the powellite formation. This result could therefore show that $\mathrm{Gd}^{3+}$ ions in network former positions enter mainly in the powellite phase. D. Caurant et al. [9] proposed that $\mathrm{Mo}^{6+}$ ions are in depolymerized regions of the glass and could be precursors of the nucleation stage. According to this work, the decrease of $\mathrm{Gd}^{3+}{ }_{[n . f]}$ relative concentration could show the presence of these ions in the vicinity of the depolymerized parts of the glass. X-ray results did not revealed a change in size or concentration of powellite, therefore analysis with imaging techniques like SEM (scanning electron microscope) are in progress and have shown to be a good way to study the powellite size evolution.

\section{Conclusion}

The study of two series of glass-ceramics belonging to the system $\mathrm{SiO}_{2}-\mathrm{B}_{2} \mathrm{O}_{3}-\mathrm{Na} 2 \mathrm{O}-\mathrm{CaO}-$ $\mathrm{Al}_{2} \mathrm{O}_{3}-\mathrm{MoO}_{3}$ with increasing $\mathrm{MoO}_{3}$ content highlights two main points. The considered synthesis protocol leads to glass-ceramics containing powellite in a glassy matrix under various heat treatments. No poorly durable $\mathrm{Na}_{2} \mathrm{MoO}_{4}$ phase was detected by XRD for $\left[\mathrm{MoO}_{3}\right]$ $\leq 5 \mathrm{~mol} \%$. The XRD study also showed that an increase of $\mathrm{CaO}$ content may favor the $\mathrm{CaMoO}_{4}$ crystallization. EPR measurements revealed a complex spectrum only observed in 
glass-ceramics containing powellite, which could be associated to $\mathrm{Gd}^{3+}$ ions incorporated into the crystalline phase. 


\section{References}

[1] X. Orlhal, C. Fillet, J. Phalipou, Mat. Res. Soc. Symp. Proc, 556 (1999) 263-270.

[2] W. Lutze, J. Borchardt, A.K. Dé, Scientific Basis for Nuclear Waste Management I, Ed. G. J. McCarthy. PlenumPress, New York (1979) 69-81. (1979) 69-81.

[3] R.J. Short, R.J. Hand, N.C. Hyatt, Mat. Res. Soc. Symp. Proc, 757 (2003) 141-146.

[4] I. Bardez, D. Caurant, J.L. Dussossoy, P. Loiseau, C. Gervais, N. Baffier, C. Fillet, Nucl. Sci. Eng., 153 (2006) 272-284.

[5] E. Malchukova, B. Boizot, D. Ghaleb, G. Petite. J. Non-Cryst. Solids, 352 (2006) $297-$ 303.

[6] S. Simon, I. Ardelean, S. Filip, I. Bratu, I. Cosma, Sol. State Comm., 116 (2000), 83 - 86

[7]J. Kliava, I. Edelman, A. Potseluyko. J. Magn. Magn. Mater, 272-276 (2004) pp e1647e1649.

[8] R. J. Landry, J. Chem. Phys., 48 (1968) 1422-1423.

[9] D. Caurant, O. Majérus, E. Fadel, A. Quintas, C. Gervais, T. Charpentier, D. Neuville. J. Nucl. Mater., 396 (2010) 94-101.

[10] O. Cozar, D.A. Magdas, I. Ardelean, J. Non-Cryst. Solids, 354 (2008), 1032-1035

[11] L. Gacem, A. Artemenko, D. Ouadjaout, J. Chaminade, A. Garcia, M. Pollet, O. Viraphong, Solid State Sciences, 11 (2009), 1854 - 1860

[12]D. Caurant, O. Majerus, E. Fadel, M. Lenoir, J. Am. Ceram. Soc., 90 (2007) 774-783.

[13]D. Caurant, P. Loiseau, I. Bardez, C. Gervais. J. Mater. Sci., 42 (2007) 8558-8570. 


\section{Figure Captions}

Figure 1: Influence of Ca concentration on the XRD patterns of different Mo glass-ceramics. (a) M225, (b) M125, (c) M25, (d) M15, (e) M27, (f) M17, (g) M27 inclusions, (h) M17 separated phase. A scale factor of 0.22 was applied to patterns $(\mathrm{g})$ and $(\mathrm{h})$ for clarity reasons. (c: $\mathrm{CaMoO}_{4}$ (JCPDS 01-077-2238), *: $\mathrm{Na}_{2} \mathrm{MoO}_{4}$ (JCPDS 01-073-1797) or $\mathrm{Na}_{2} \mathrm{MoO}_{4}, 2 \mathrm{H}_{2} \mathrm{O}$ (JCPDS 01-070-1710)).

Figure 2: Influence of Mo concentration on the EPR spectra (MP $=20 \mathrm{~mW}$ ) of different M2x glass-ceramics. EPR lines corresponding to $\mathrm{Gd}^{3+}$ inserted in powellite in M25 sample are circled. Inset: evolution of the ratio $\mathrm{Gd}^{3}{ }_{+[\mathrm{n} . \mathrm{f}]} / \mathrm{Gd}^{3+}{ }_{[\mathrm{n} . \mathrm{m}]}$ with molybdenum concentration in $\mathrm{M} 2 \mathrm{x}$ samples (solid line) and M1X samples (dashed line), line is only a guide for the eyes.

Figure 3: EPR spectra $(\mathrm{MP}=20 \mathrm{~mW})$ of powellite $\mathrm{CaMoO}_{4}$ (solid line) and $\mathrm{CaMoO}_{4}$ doped with $0.15 \mathrm{~mol} \%$ of $\mathrm{Gd}_{2} \mathrm{O}_{3}$ (dashed line). Only g values observed in the glass-ceramics are reported here.

Figure 4: (a) M225 heat treated at $1100^{\circ} \mathrm{C}$ during $4 \mathrm{~h}$. (b) M225 heat treated at $1100^{\circ} \mathrm{C}$ during 22h. (c) EPR spectra of heat treated samples, (1) M25 heat treated $2 \mathrm{~h}$ at $950^{\circ} \mathrm{C}$ and $2 \mathrm{~h}$ (solid line) or $20 \mathrm{~h}$ (dashed line) at $1100^{\circ} \mathrm{C}(2) \mathrm{M} 25$ heat treated $4 \mathrm{~h}$ (solid line) or $22 \mathrm{~h}$ (dashed line) at $1100^{\circ} \mathrm{C}$. 
Figure 1

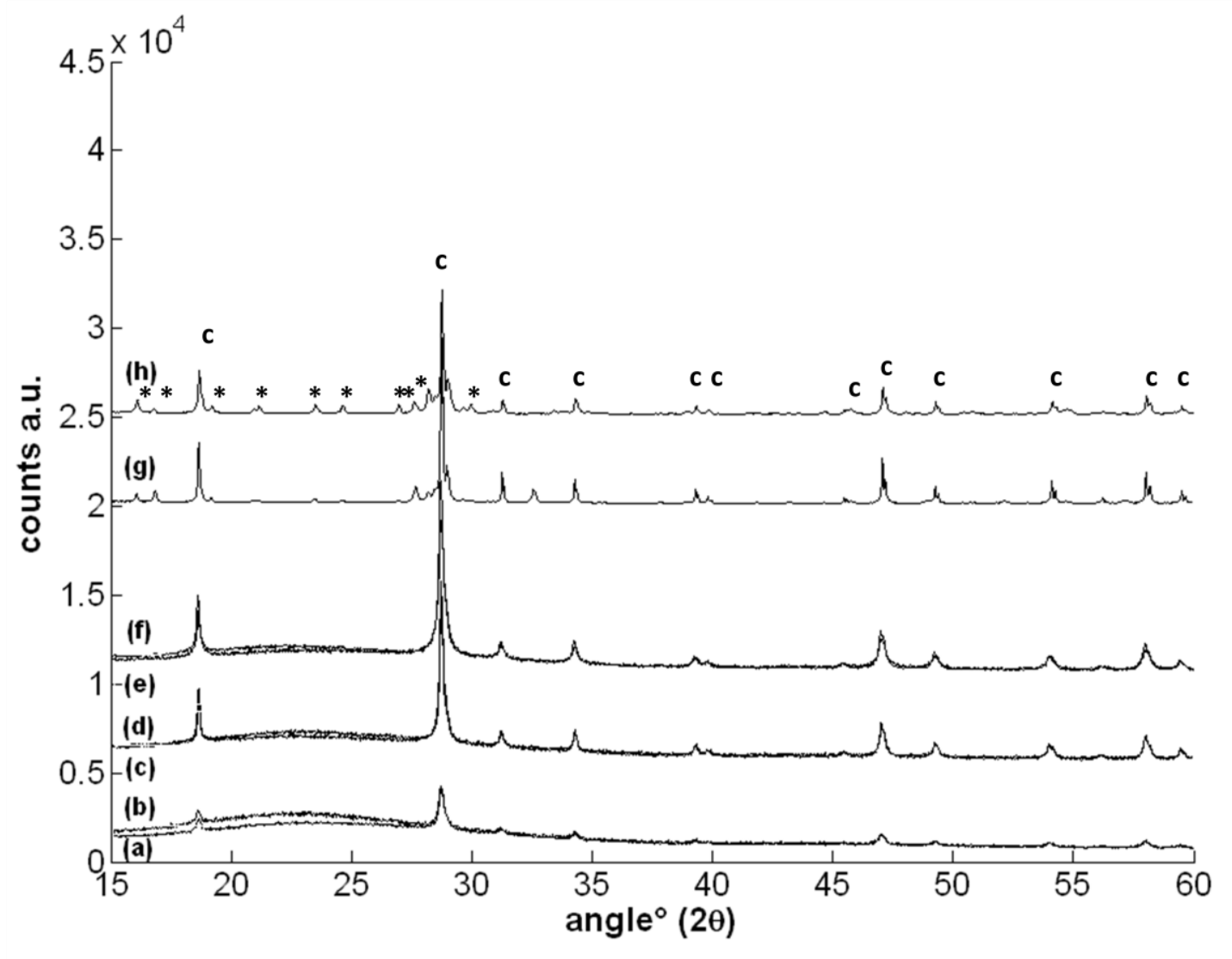


Figure 2

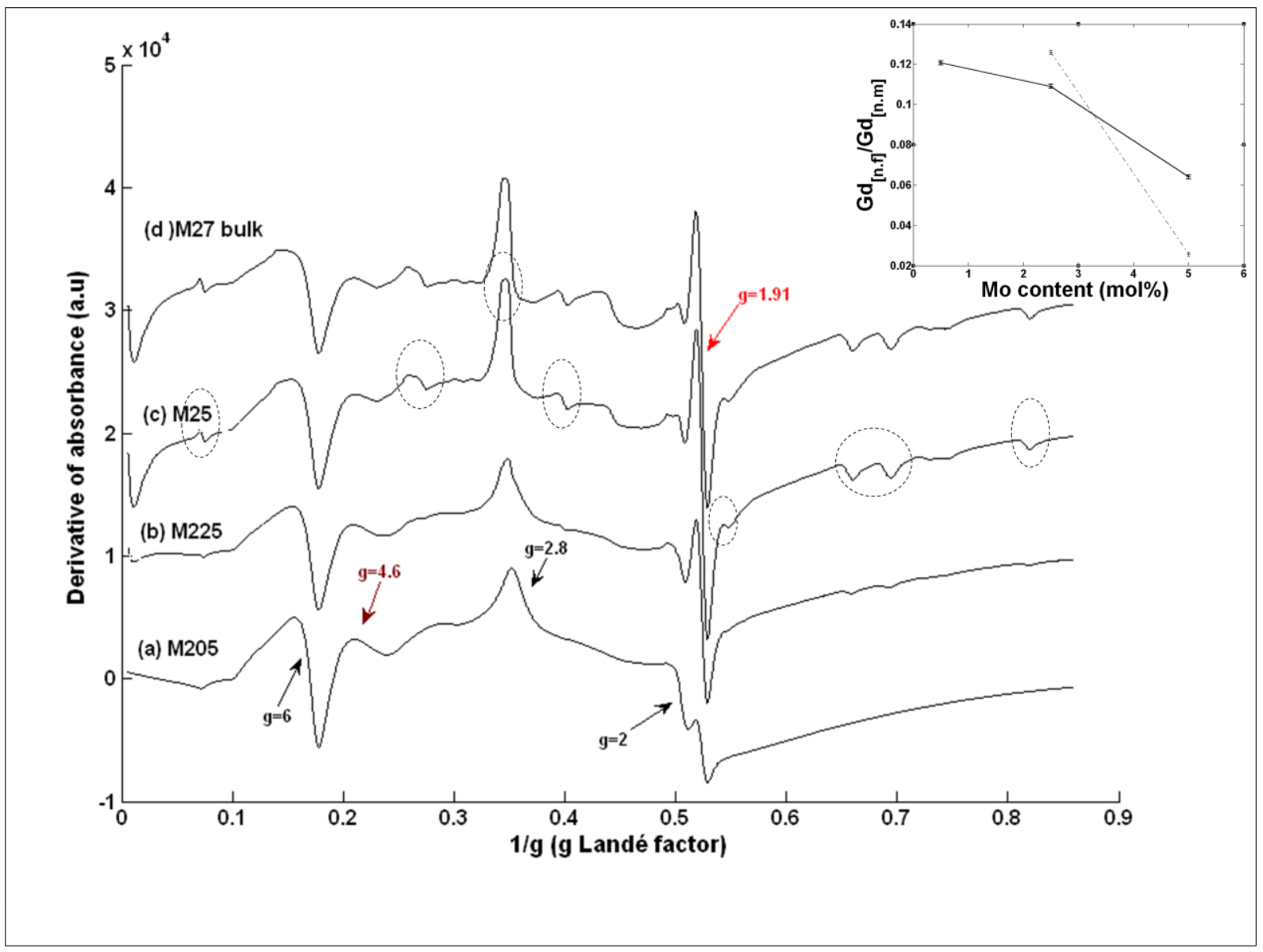


Figure 3

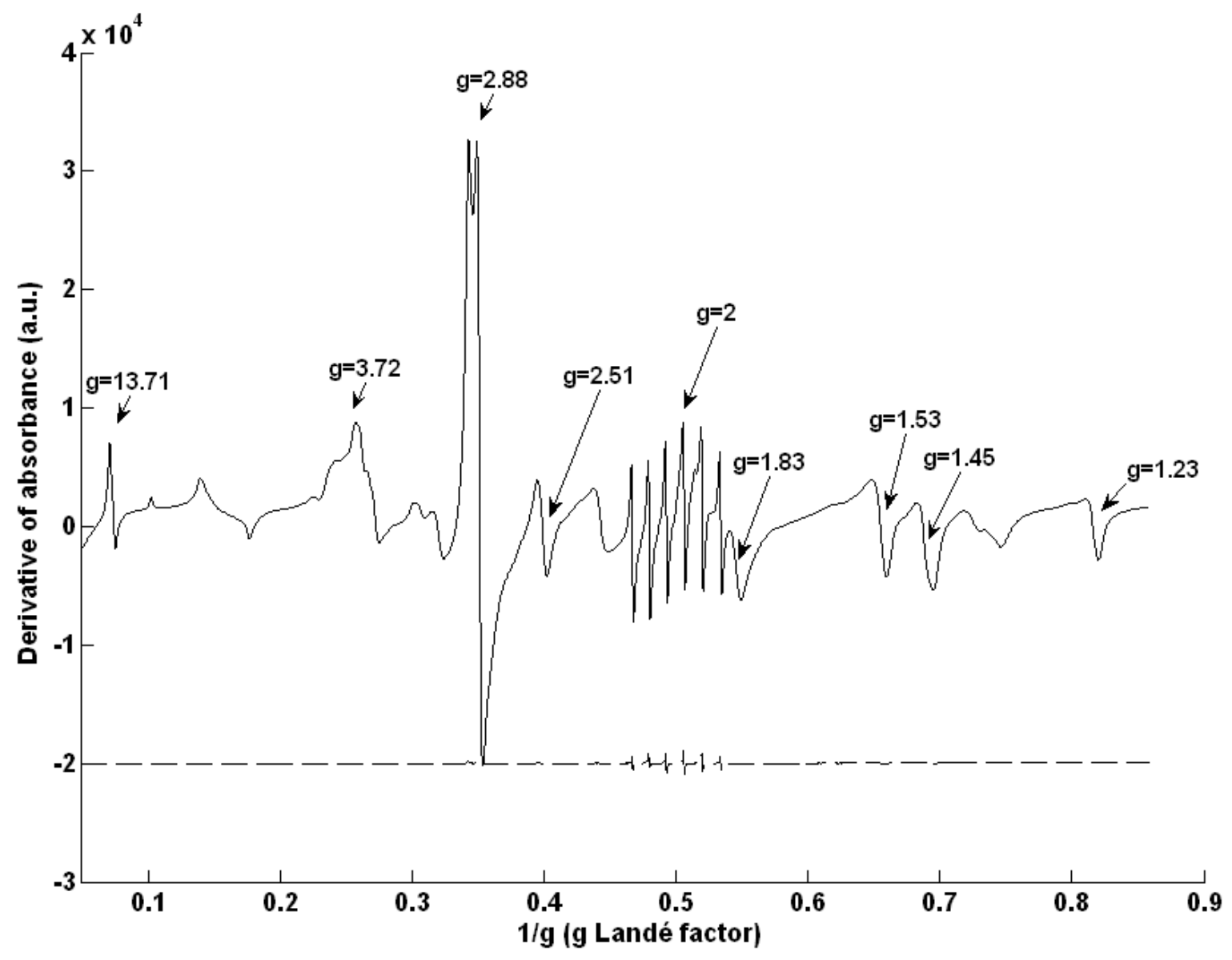


Figure 4
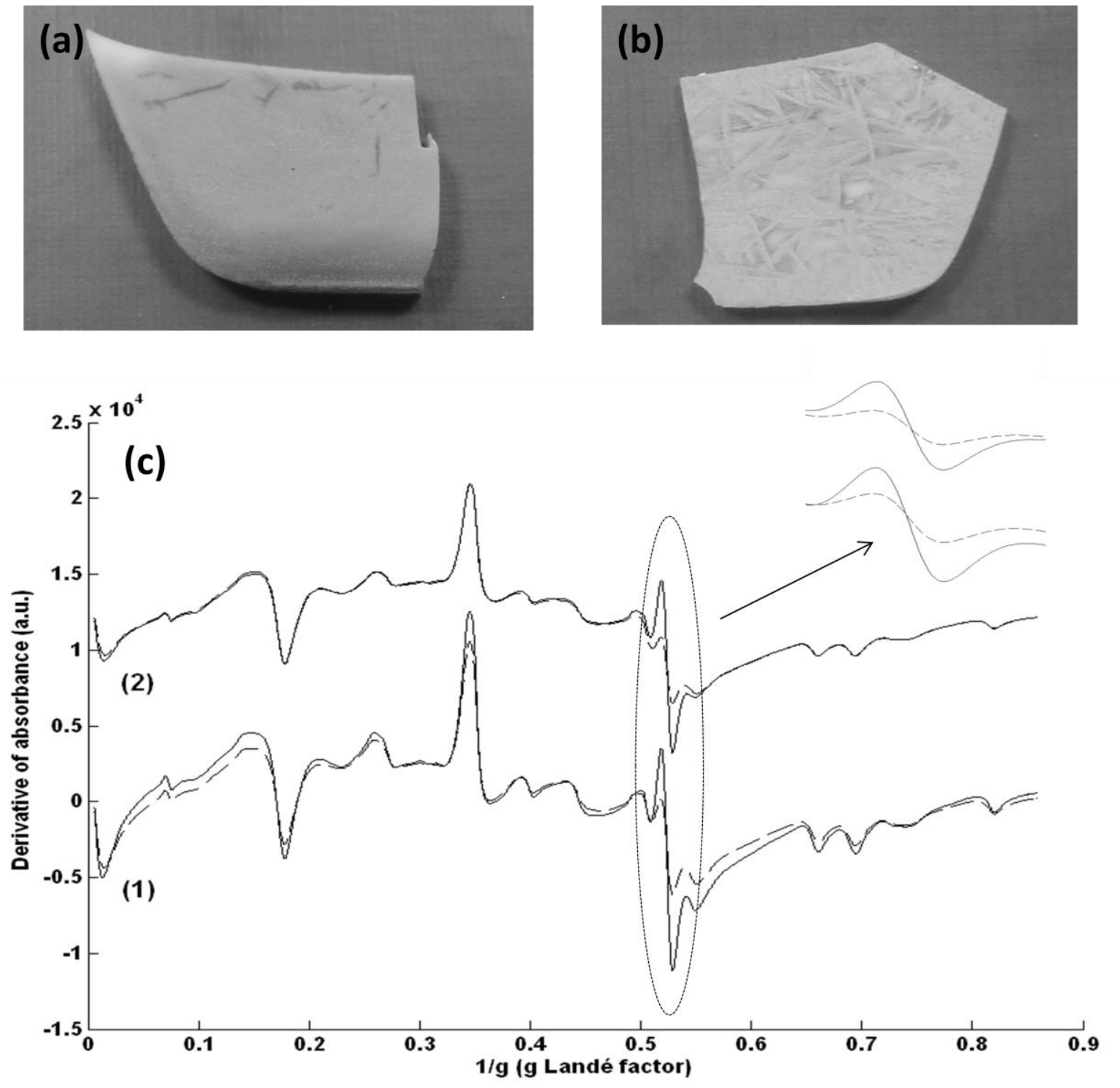